\title{
Andrea Pagni \\ EI lugar de la traducción en los proyectos editoriales argentinos entre 1850-1890
}

La fórmula "Literatura de la independencia e independencia de la literatura" designa el proceso que en América Latina va, a lo largo del siglo XIX, del uso de la literatura al servicio de la política hasta la autonomización del campo literario. Ese proceso tuvo lugar en la etapa de la llamada "organización nacional" que implicó una reestructuración de la sociabilidad y de las instituciones, y condujo también a la reorganización del aparato de importación cultural, en el que la traducción ocupó un lugar de importancia.

En lo que sigue, me referiré a los usos de la traducción durante ese proceso, partiendo de premisas y tesis basadas en posiciones teóricas de los estudios de traducción y focalizando el formato de las publicaciones periódicas como medios privilegiados de circulación de las traducciones, en dos momentos claves del proceso que conduce a la "independencia de la literatura" en Argentina: los comienzos de la organización nacional después de 1852 , y los umbrales de 1880 , cuando se inicia la autonomización del campo literario en Argentina.

\section{Traducción y literatura nacional: dos premisas y tres tesis}

La primera premisa teórica sostiene que la traducción juega un papel fundamental en el proceso de constitución de una literatura nacional y también en el proceso de autonomización del campo literario. Esta premisa parecería enunciar una paradoja, porque por lo general suele pensarse la traducción como un factor de subordinación a la literatura extranjera, y no como parte de una agenda nacionalista.

Itamar Even-Zohar sostiene que la literatura en traducción es parte integral de las fuerzas innovativas del sistema literario; en épocas de surgimiento de nuevos modelos, las traducciones son medios para la elaboración de los nuevos repertorios. Él señala tres situaciones en que la traducción adquiere mayor importancia: cuando una literatura es "joven" y está en formación, la traducción sirve para poner a fun- 
cionar la lengua literaria en distintos géneros y formas haciéndola accesible a un público emergente; cuando una literatura es periférica, o menor, o ambas cosas, la traducción contribuye a ampliar el repertorio; en momentos de crisis, de agotamiento de modelos o de vacíos literarios la traducción impulsa el cambio (Even-Zohar 2004: 200-201). Con frecuencia son justamente aquellos escritores que ocupan las posiciones más destacadas dentro del campo, los que realizan las traducciones que inciden con mayor fuerza en los procesos de innovación del sistema.

La segunda premisa sostiene que el surgimiento de un público lector es una condición de posibilidad de la existencia de una literatura nacional, y no su resultado. También esta premisa puede parecer paradójica, porque tendemos a pensar, por el contrario, que la literatura nacional precede y forma a sus lectores. Sergio Pastormerlo, que estudió el fenómeno de emergencia de mercados editoriales en Argentina hacia 1880 , observa que entre 1870 y 1880 , como consecuencia de una exitosa política de alfabetización, surge en Argentina un nuevo público lector y con él aparece una nueva demanda de mercado que estimula económica y simbólicamente la producción cultural. Este fenómeno tiene "como correlato la aparición de nuevos escritores" -la llamada Generación del 80. Con este cambio se inicia "una separación entre cultura letrada y clase dominante", ya que de ahí en más la literatura dejaría de responder exclusivamente a los gustos, creencias e intereses de esa clase, sino también a los de un público más amplio. El rotundo éxito de lectura de Martín Fierro, entre 1874 y 1879 , solamente es posible porque ya existía un público de lectores capacitados (Pastormerlo 2006: 2).

Si los lectores preceden a la literatura nacional, hay que pensar la formación de esos lectores por fuera del contexto de una literatura nacional, todavía inexistente, y en el marco de una pedagogía de la lectura en la que la importación cultural desempeña un papel no desdeñable. De ahí que la primera tesis sostenga que la capacitación de esos lectores, que son condición de posibilidad de la existencia de una literatura nacional, se realizó en Argentina en buena medida a través de traducciones que ocupan un lugar importante en las agendas de la clase política en la segunda mitad del siglo XIX.

En momentos previos a la autonomización, cuyo comienzo suele situarse hacia 1880 , es decir cuando cultura letrada y clase dominante 
todavía coinciden, el gobierno nacional propicia en Argentina una política educativa que contribuye al surgimiento de un amplio público lector. Para llevar a cabo esa agenda pedagógica, se requieren textos legibles. Esta biblioteca pedagógica fue en buena medida una biblioteca de traducciones, realizadas también por los letrados, que en este caso no traducían para sus pares, sino para un público al que había que educar. A esta etapa puede aplicarse la observación de Lawrence Venuti, cuando señala que las agendas nacionalistas de traducción fueron promovidas muchas veces por las elites culturales con el objetivo de imponer sus propios valores (lingüísticos y literarios, pero también políticos y sociales) al conjunto de la población, privilegiando ciertas formas y prácticas culturales, ciertas audiencias, en desmedro o con exclusión de otras. Analizando los resultados de algunas de esas políticas nacionalistas de traducción, Venuti observa también que ellas no son el efecto de una mera imposición por parte del sector letrado y dominante:

La efectividad comunicativa de una traducción depende de su capacidad de responder a los supuestos culturales, a las expectativas e intereses que definen la situación social en la que el traductor escribe. Las agendas nacionalistas, que no buscan sólo comunicar el sentido del texto extranjero, sino usar esos textos para construir identidades nacionales, tienen que tomar en cuenta, tácticamente, las formas lingüísticas, los valores culturales y los grupos sociales, siempre organizados jerárquicamente, en su momento histórico. Este aspecto marca inevitablemente el proceso de traducción como así también el tipo de identidad nacional que el traductor procura establecer (Venuti 2005: 192). ${ }^{1}$

Para promover efectivamente la elaboración de lenguas, culturas e identidades nacionales, es necesario que las traducciones sean aceptadas por un público amplio y variado (Venuti 2005: 178) cuyas expectativas no coinciden con las del sector letrado.

La segunda tesis sostiene que las traducciones de los letradostraductores exponen la contradicción básica del proyecto pedagógico, consistente en pretender formar un público nacional de ciudadanos lectores según los supuestos y las expectativas del sector social al que los traductores pertenecen -que difieren sensiblemente de los supuestos y las expectativas de ese nuevo público en formación. ${ }^{2}$

Traducción A.P.

2 Para el concepto de "letrado-traductor" en Argentina ver Willson (2008). 
La tercera tesis afirma que los proyectos de traducción puestos en marcha en Argentina antes de fin del siglo XIX fracasan porque la agenda pedagógica de los letrados argentinos no respondía a la demanda del incipiente público lector, no tenía en cuenta sus intereses y gustos. Los proyectos editoriales van a tener éxito solamente cuando comienzan a tomar en cuenta la demanda del público lector, privilegiando un gusto que ya no es el de la clase letrada, sino el de las clases en formación.

\section{El estatuto de la traducción en El Plata Científico y Literario (1854-1855)}

A mediados del siglo XIX, la fundación de revistas formula objetivos pedagógicos y democratizadores. En el prospecto que encabeza el primer número de El Plata Científico y Literario. Revista de los Estados del Plata sobre Lejislación, Jurisprudencia, Economía-Política, Ciencias Naturales y Literatura (1854), su director Miguel Navarro Viola escribe:

Todos, de consiguiente, deben saber y todos deben estudiar. Porque saber y estudiar son términos correlativos.

Mas como no á todos es dado hacerlo por principios, pasar una porción de su vida en los bancos universitarios, - de ahí la necesidad de tentar otros medios de instrucción menos metódicos, menos largos, pero más populares, más vastos, al alcance de todos (Navarro Viola 1854a, I: 1).

La revista se propone como alternativa "popular" a la formación académica, con una nota distintiva también respecto del diario:

Ocupado casi siempre en materias del momento, teniendo que abarcar cuanto ve en la instable marcha de los sucesos, el Diarismo es una especie de Daguerrotipo en que el sol de cada día dibuja con nuevos coloridos todos los objetos que alcanza á iluminar. [...]

Las grandes generalizaciones, los estudios reposados y los trabajos preparados no pueden ser sino del resorte de publicaciones más detenidas, más elaboradas (Navarro Viola 1854a, I: 1).

A continuación, Navarro Viola enuncia lo que será la política de importación cultural de la revista, en esa línea de la doble mirada que ya había enunciado Echeverría:

aprovechar la verdad donde quiera que se encuentre, ora nos venga del estrangero, ora la hallemos en nuestro propio clima, la verdad en todo lo que nos concierna, la verdad no servilmente copiada, sino aplicada a nuestras necesidades (Navarro Viola 1854a, I: 2). 
Hacia el final del prospecto, el director se refiere explícitamente a las traducciones, que constituyen uno de los pilares del proyecto, ofreciendo una "garantía para las [...] que aparezcan en nuestra Revista":

Ellas irán firmadas por el traductor á la par del autor, como un secretario suyo. Y a fé que merece ese lugar y esa clasificación el que está en los secretos rítmicos del estilo del autor, y que para revelarlo con propiedad, necesita naturalmente saber escribir, tener también estilo. Por eso vemos que los buenos escritores nunca han desdeñado prohijar sus traducciones, pues saben el trabajo que cuestan y el mérito de que son susceptibles; y que justamente las únicas buenas traducciones son las hechas por personas acostumbradas á escribir. Así las que aparezcan en nuestra Revista se diferenciarán en mucho de esas traducciones de pacotilla que nos inundan diariamente en mengua de los originales y de la buena locución española (Navarro Viola 1854b, I: 6; énfasis A.P.).

"Esas traducciones de pacotilla" son las que publican los folletines de los diarios, redactadas por traductores anónimos sin "estilo" y en un español deficiente. Llaman aquí la atención la conciencia de que la traducción es un instrumento fundamental de difusión cultural, la valoración del estilo del traductor, y la referencia a la cantidad de traducciones anónimas que circulan en 1854 en el Río de la Plata, la mayor parte, como sabemos, importadas de los folletines españoles, y de las que la revista, por medio de su director, se distancia abiertamente. Es evidente que la traducción está pensada aquí como un instrumento de pedagogía estética.

El Plata Científico y Literario publicó entre 1854 y 1855 siete números de 200 páginas cada uno. En el primero aparece en traducción del mismo Miguel Navarro Viola, "Graziella", una novela corta de Afonso de Lamartine (1854: 161-203), ${ }^{3}$ que había sido publicada originalmente como parte de sus Confidences en el folletín de $L a$ Presse en 1849, y había sido editada en forma de libro en París en 1852.

\section{Lectura y traducción en "Graziella" de Lamartine (1844-1852)}

¿Por qué elige Navarro Viola traducir justamente esta obra de Lamartine? Evidentemente, se trata de una decisión fuerte, puesto que la publica en el primer volumen de El Plata..., y le reserva 40 de las

3 Todas las citas de la traducción se hacen por esta edición de 1854, consignándose en cada caso la página que corresponde. 
200 páginas de la revista. Para responder a esta pregunta, tengo que dar un rodeo y contextualizar la figura de Lamartine y su obra "Graziella".

El escritor francés, que durante la Monarquía de Julio había ido abandonando los temas románticos que lo habían hecho famoso como poeta de las Meditations, e interesándose más por cuestiones políticas y sociales en abierta oposición a la política de Louis Philippe, el rey burgués, y su ministro Guizot, se convirtió entre la redacción de "Graziella" y su publicación en figura protagónica de la Revolución de 1848. ${ }^{4}$ Una de sus mayores preocupaciones era la educación de las clases populares: en un artículo de 1843 titulado "Des publications populaires", criticaba que las clases populares carecieran de material adecuado de lectura; y en 1852, el mismo año en que "Graziella" aparecía en forma de libro, Lamartine fundó un periódico mensual titulado Le Civilisateur, que se vendía a muy bajo precio y cuyo objetivo era la formación moral y la instrucción histórica de los sectores populares. La publicación de "Graziella", desgajada del texto autobiográfico de las Confidences, es en cierto modo una concesión al gusto del público y a la moda de las novelas, género que Lamartine había evitado hasta entonces. ${ }^{5}$

"Graziella" tiene un narrador en primera persona, que relata un recuerdo de su juventud, cuando a los 18 años, durante un viaje a Italia con un amigo, se había hospedado durante algunos meses en casa de una familia de pescadores en la isla de Prócida, y despertado el amor de Graziella, la hija adolescente del pescador, de la que el joven tam-

4 En 1854, cuando se publica en el Río de la Plata la traducción, Lamartine era no sólo el escritor romántico consagrado, cuya estética había sido puesta en jaque por Balzac, sino también una figura central de la Revolución de 1848 durante la que había defendido a ultranza los principios republicanos de 1789. Después del golpe de estado de Louis Napoleón en diciembre de 1851, había sido desplazado abruptamente de la arena política; sobre la postura y actuación política de Lamartine ver Fortescue (1983).

5 Gleize, en quien se basa esta parte del artículo, comenta que a partir de 1830 Lamartine había manifestado el deseo de abandonar la lírica, pero que entre 1843 y 1849 le importa menos un cambio de género que una transformación del público lector. La elección misma de la prosa es testimonio de su preocupación por llegar a los nuevos lectores, lo que se evidencia en el hecho de que publique las Confidences en el folletín en La Presse, teniendo en cuenta que se había negado explícitamente a publicar su Histoire des Girondins en forma de folletín, para no devaluar la obra (Gleize 1997: 52). 
bién creía haberse enamorado. La casta relación termina abruptamente cuando el narrador recibe una carta en la que se le pide que vuelva a Francia, porque su madre está enferma y en peligro de muerte. En esa situación trágica, el hijo decide irse, pero le promete a Graziella volver. Una vez en París, sin embargo, olvida la promesa y al tiempo se entera de que Graziella ha muerto de pena. Años más tarde, a la vista de un ataúd cubierto por un lienzo blanco, el narrador recuerda y relata aquella historia de su juventud.

El momento central del relato, lo constituye una escena de lectura y traducción, que "plantea en términos ficcionales la cuestión de la posibilidad de que la literatura conmueva a un público popular" (Gleize 1997: 52). ${ }^{6}$ En el círculo de la familia de humildes pescadores que por supuesto no saben leer, el narrador lee en voz alta, traduciendo directamente al italiano Pablo y Virginia, la novela de Bernardin de Saint-Pierre:

[...] nos pusimos una noche à leerles Pablo y Virginia: yo fui quien traduje este libro leyéndolo, porque estaba tan acostumbrado á leerlo, que lo sabía, por decirlo así, de memoria. Familiarizado por mi larga residencia en Italia con la lengua, no me costaba trabajo hallar las expresiones y fluían de mis lábios como una lengua materna. Apenas comencé esta lectura, cuando cambiaron las fisonomías de nuestro auditorio y tomaron el aire de atencion y recogimiento que es indicio seguro de la emocion del corazon. [...] Graziella, que se mantenía ordiariamente algo lejos, se aproximó insensiblemente á mí, como si la hubiera fascinado un poder de atracción oculto en el libro. [...] abriendo cuando podía los ojos, miraba unas veces el libro y otras mis lábios, de donde fluia la relación, y otras en fin el vacío entre mis lábios y el libro, como si hubiera buscado con la mirada el invisible espíritu que me lo interpretaba. [...] Antes de llegar á la mitad de la historia, la pobre niña habia olvidado su reserva algo salvage conmigo. Sentia el calor de su respiracion sobre mis manos.

[...] Cuando llegué al punto en que Virginia, llamada á Francia por su tia, siente, por decirlo así, dividirse su ser en dos y se esfuerza por consolar á Pablo debajo de los plátanos, hablándole de su vuelta y mostrándole la mar que va á llevarla, cerré el libro y aplacé su lectura para el día siguiente.

Este fué un golpe fatal para aquellas pobres gentes. Graziella se puso de rodillas delante de mí y luego delante de mi amigo para suplicarnos q' acabásemos la histori[a]. Pero todo fué en vano. Queríamos prolongar el interés para ella y el encanto de la prueba para nosotros. [...] Su fisonomía, tan serena y risueña en la calma, aunque algo austera, habia tomado repentinamente de la pasión y del enternecimiento simpático de

6 Traducciones de Gleize A.P. 
aquella relacion, algo de la animacion, del desorden y de lo patético del drama. $[. .$.

La jóven sentia su alma, hasta allí dormida, despertarse en ella en el alma de Virginia. Parecía haber adquirido seis años de madurez y experiencia en aquella media hora (180-181).

\section{El narrador comenta:}

¡Maravilloso poder de un libro que obra sobre el corazon de una niña rústica, y de una familia ignorante con toda la fuerza de una realidad, y para quienes la lectura de ese libro es un acontecimiento en la vida del corazón!

La razón de este fenómeno estaba, en que asi como yo traducía el poema, el poema había traducido la naturaleza, y en que aquellos acontecimientos tan sencillos [...] son cosas que todo el mundo siente y comprende desde el palacio hasta la cabaña del pescador (181).

La crítica francesa ha leído esta escena en el marco de las preocupaciones de Lamartine por la relación entre literatura y lectura popular y sobre el trasfondo del éxito de la novela de folletín. Resumo a continuación los resultados de la lectura e interpretación de Gleize (1997), ${ }^{7}$ para vincularlos luego con la pregunta formulada antes de iniciar este rodeo por la literatura francesa: ¿por qué elige Navarro Viola traducir justamente esta obra de Lamartine?

Esa escena de traducción y lectura se lee como "una especie de comunión literaria" (52) en la que se borran todas las diferencias sociales y también la oposición fundamental entre naturaleza y cultura. Lamartine presenta un espacio utópico en el que un libro de la más alta cultura literaria llega a un público "totalmente ajeno al mundo de la imprenta" (52). El paulatino acercamiento físico de Graziella al libro que la fascina, simboliza ese borramiento de las distancias sociales (53). La voz de lector-traductor-narrador opera como intermediaria en este encuentro entre el libro y la familia iletrada. ${ }^{8}$ Pero esa "suspensión de los antagonismos y el borramiento de las distancias socioculturales" (54) sólo son posibles en el marco de una asimetría evidente. Porque si bien el narrador puede cruzar con toda libertad la frontera que separa a la cultura de la naturaleza, a las clases altas del pueblo, a las pasiones del espíritu de las pasiones del corazón, e incluso traducir

7 Los datos de paginación corresponden en este apartado siempre a Gleize (1997).

8 Tomando en cuenta la dimensión autobiográfica de las Confidences, puede concluirse que Lamartine se imagina aquí en el rol de quien inicia a los sectores populares iletrados a la cultura de la sensibilidad. 
al italiano sin mayores dificultades, ni los pescadores ni Graziella pueden abandonar del mismo modo su clase y su cultura "natural" (54). Y si el narrador es aceptado como miembro de la familia, la comunión es provisoria y termina cuando la realidad de su condición social lo llama al orden. Él puede irse, Graziella no puede retenerlo, y tampoco irse con él.

También en las actitudes del lector-traductor-narrador y de su oyente iletrada ante la ficción encontramos una diferencia fundamental. Porque mientras él mantiene la calma y el control sobre lo que va leyendo, ella se identifica con la ficción y se ve envuelta en emociones cada vez menos controlables. Él "comparte la posición de poder del autor" (54), puede interrumpir la lectura y hacerse desear reproduciendo la técnica del folletín, puede gozar de las lágrimas que provoca, insensible a los ruegos de Graziella. En ella, la lectura suscita emociones, no palabras; es su cuerpo el que reacciona, y lo que le ocurre durante la lectura es "una doble iniciación ambivalente a la literatura y a la pasión" (55). Gleize lee "Graziella" como "una etapa esencial en la reflexión de Lamartine sobre las condiciones de posibilidad de la literatura popular" y femenina, como "una especie de escena experimental", en la que "se descubren los posibles efectos nocivos de una literatura que no ha sido concebida específicamente" para esa lectora iletrada confrontada con ella (58).

En 1844, mientras Lamartine escribe "Graziella", aparece Los Tres Mosqueteros de Dumas y comienzan a publicarse los exitosos folletines El Conde de Montecristo y El Judio Errante (58). "Graziella", con su trama simple y desprovista de grandes peripecias, con su escaso elenco de personajes y su tonalidad más patética que dramática, es expresión de una estética diferente de la del folletín -pero coincide con él en algunos rasgos, como por ejemplo la distribución en capítulos breves y sobre todo la concepción del protagonista como "héroe noble y generoso" que detenta con exclusividad "la palabra iniciática y seductora" (58). Al proponer a Pablo y Virginia como modelo de literatura popular, Lamartine reactualiza en "Graziella" un modelo que podría pensarse pasado de moda, sin embargo, incluso durante el Segundo Imperio es una de las pocas novelas que compite exitosamente con el folletín. Y tiene un éxito duradero, porque "Graziella" pasará a integrar, a partir de 1853, la colección Bibliothèque des chemins de fer de Hachette, donde será reeditada en 1854, 
1855, 1857 y 1858 (59) -y en el Río de la Plata, será traducida por uno de los letrados más conspicuos de la Confederación Argentina.

\section{4. "Graziella", de Navarro Viola: la traducción contra el folletín}

Traducir no es solamente trasladar de una lengua a otra lengua, sino también desplazar de una literatura a otra, de una cultura a otra, de un contexto a otro contexto. En la Argentina de 1854, "Graziella" no puede funcionar a manera de escenificación experimental sobre las posibilidades, limitaciones y contradicciones de una educación literaria del pueblo, porque a diferencia de la Francia de Lamartine, no existe todavía ese público lector amplio, que es objeto de la preocupación del escritor francés y que aparece representado en la figura de esa lectora/oyente ingenua que es Graziella. Si Lamartine publica sus Confidences en forma de folletín para tratar de acercarse a la demanda de ese nuevo público francés -y "Graziella" es un paso que da el poeta consagrado de las Meditaciones y el autor de las grandes obras de historia en esa misma dirección, hacia el lector popular-, la traducción y publicación de "Graziella" en El Plata Científico y Literario tiene por objetivo poner "al alcance de todos" una novela contra la moda de las novelas, que Navarro Viola critica en su prólogo del traductor. ${ }^{9}$

Allí escribe con desprecio sobre "esos millares de romances que causan ya una especie de neblina en la atmósfera literaria" y que "pasarán con la fiebre de la época sin dejar rastros de su existencia fugitiva"; califica a Balzac de "artista [...] mercenario" y cita a un crítico francés que se lamenta de que "el arte en vez de ser un sacerdocio" sea "una mercancía" y que los escritores de la época en lugar de vivir para escribir, escriban para vivir:

¿[q]ué oponer, pues, á ese torrente de romances [...]? ¿qué á esos libros que por lo general son los únicos que venden bien los libreros y traducen mal los traductores y que escriben peor los autores? (Navarro Viola 1854b: 161).

En la Argentina de 1854 la institución literaria es un proyecto, no una realidad. No hay escritores que escriban para vivir, ni siquiera traduc-

9 El prólogo del traductor -este es un aspecto que también hay que tener en cuenta en el momento de analizar los efectos de lectura de la traducción de "Graziella"-, destruye la ilusión autobiográfica creada por Lamartine al publicar su novela en las Confidences. 
tores que traduzcan para vivir; hay una gran cantidad de folletines traducidos en la prensa periódica y Navarro Viola espera competir con su revista con y contra el folletín de los diarios y alcanzar y seducir a esos lectores de folletines mal traducidos, que no constituyen todavía un público popular. Se trata de presentar una oferta de lectura alternativa, para la que prevé dos tipos de novelas: la novela histórica "que instruye" - no la de Dumas, sino la de Walter Scott, precisa- y la novela sentimental, categoría en la que coloca explícitamente a "Graziella". "Plegándonos, pues, a la exigencia de novelas, las que aparezcan en el 'Plata científico y literario' tendrán esa limitación", explica (Navarro Viola 1854b: 161-162).

¿Se trata, entonces, de ofrecer literatura "al alcance de todos", como afirmaba el prospecto? Habría que precisar: al alcance de todos los que acepten "esa limitación" y rechacen la literatura de folletín mal traducida y peor escrita, "fácil, accesible á todo el mundo", prefiriendo "la novela que instruye, la novela histórica" y "la novela sentimental, la novela del corazon" (Navarro Viola 1854b: 161). "Todos" no son, en rigor, "todo el mundo", sino aquellos lectores cuya competencia de lectura les permite distinguir y elegir. El proyecto editorial se presenta con un matiz pedagógico y democrático, pero va dirigido a un público letrado, y no al público popular de Lamartine, inexistente en la Argentina de 1854.

"Graziella" en la traducción de Navarro Viola no pone en escena una lectura, sino una escritura, la escritura del traductor que traduce bien y escribe bien, y presenta un modelo de traducción esperando que haga escuela. Se trata de contribuir mediante la traducción de una obra considerada valiosa a elaborar una lengua literaria para la nación.

Desde el punto de vista de Navarro Viola una buena traducción es, como lo demuestran sus estrategias, una traducción que no aclimata y que respeta a un tiempo la dicción del autor y la locución de la lengua meta. Retomando y variando el slogan de la revista, podría decirse que la traducción se pone al alcance de todos aquellos lectores que estén dispuestos a acercarse al texto. ${ }^{10}$ Navarro Viola presenta la traducción como una escritura valiosa en el marco de un proyecto de

10 Con Schleiermacher diríamos que el traductor acerca el lector al texto, y no el texto al lector. 
formación de una literatura nacional y un público según los criterios de la propia clase letrada. En realidad, traduce para sus pares, convencido de que la traducción cumple un papel fundamental en la construcción de la cultura nacional en la que está empeñada la revista.

\section{El surgimiento de un nuevo público lector}

Es solamente en la década de 1870 cuando surge en Argentina un público lector popular. Hasta entonces, como se ha observado en el caso de Navarro Viola, la elite letrada se había visto a sí misma "como lectora exclusiva y excluyente de los libros que gestaba" (Eujanián 1999: 558). ${ }^{11}$ La política de los gobiernos de la organización nacional conduce por diversos medios, básicamente la creación de escuelas, a que en la década de 1870 vaya surgiendo en el Río de la Plata un mercado editorial en sincronía con la aparición de un nuevo público lector de carácter popular "surgido masivamente de las campañas de alfabetización" (Prieto 1988: 13).

Este fenómeno provoca un cambio en la actitud de la elite. Para que los sectores populares, provenientes en buena parte de la inmigración, se conviertan en público lector, es necesario que quienes tienen en sus manos los instrumentos de producción y difusión de la cultura escrita, es decir los miembros de esa elite letrada, interpelen a esos sectores populares como nuevo público al que es deseable alcanzar.

La expansión de la prensa periódica juega un papel importante en este proceso. En la década del setenta, el sistema de suscripciones de diarios es reemplazado por la venta callejera y se abren así nuevos canales de circulación, porque ya no es necesario reunir el monto de una suscripción para leer regularmente el periódico. En los folletines de los diarios se siguen publicando, ahora con mayor éxito de ventas que a mediados de los cincuenta, novelas por entregas, como las de Émile Zola, alejadas "del canon literario de la elite" y de sus "criterios de buen gusto y principios morales" (Eujanián 1999: 577). Se consolida un nuevo espacio de lectura no controlado por la elite, sino por las leyes del mercado. En sus aspectos externos, observa Adolfo Prieto, este sistema paralelo "no parece sino un remedo, una versión de se-

11 Para la configuración de los campos de lectura a partir de 1880 ver Prieto (1988). 
gundo grado del sistema literario legitimado por la cultura letrada" (Prieto 1988: 15).

Ante el éxito de ventas de esta "literatura de contenido dudoso en cuanto a sus proyecciones sociales", la clase letrada esgrime el criterio moral para "clasificar una oferta literaria cada vez más amplia y destinada a un público en expansión" (Eujanián 1999: 583). La alfabetización, que había sido prioritaria en la política argentina hasta esos momentos, se revela como un mecanismo de contención social insuficiente. ${ }^{12}$ Gana terreno "la idea de que no cualquier libro", con sólo ser barato, contribuye "a la realización del fin moral que la elite cultural creía que debía cumplir" y el problema se desplaza, de una manera mucho más perentoria que en 1854, hacia la selección: “¿qué leer?" (Eujanián 1999: 581-582). Se trata ahora, para la elite cultural, de generar una literatura que funcione como "agente civilizador y moralizador de los sectores populares", evitando que estos deriven hacia lecturas que no responden al modelo que la cultura dominante quiere consolidar en la sociedad (Eujanián 1999: 581).

\section{La Biblioteca Popular de Buenos Aires (1878-1883) como proyecto editorial}

En 1878, Miguel Navarro Viola, que después de haber sido director de El Plata Científico y Literario (1854-1855) había fundado junto con Vicente Quesada La Revista de Buenos Aires (1863-1871), lanza una colección de literatura con un título programático: La Biblioteca Popular de Buenos Aires. ${ }^{13}$ Como las "bibliotecas populares", instituciones de difusión del libro y la lectura creadas a instancias de Sarmiento durante la década de 1870 en diversos lugares de la Argentina, la colección homónima de Navarro Viola apunta justamente a esos sectores populares recientemente alfabetizados, a los que hay que educar a través de un programa de lecturas variadas, no muy extensas, convenientemente escogidas y a precios accesibles.

12 Bertoni (2001) estudia la importancia de la difusión de textos escolares para el surgimiento y consolidación de la industria editorial y de la figura del editor.

13 Ya a comienzos de los años setenta, durante la presidencia de Sarmiento y en el marco del proyecto liberal de extensión cultural, se habían creado casi 150 bibliotecas populares en todo el país, cuyo abastecimiento corría por cuenta del Tesoro Nacional, según estipulaba la ley de 1870 (Eujanián 1999: 563). 
El plan preveía la publicación de 12 tomos de entre 250 y 260 páginas por año, que reunieran cada uno un conjunto de textos con predominio de narrativa y ensayo de corte moralizante. De cada número se tiraban unos 2.000 ejemplares que se vendían a $15 \$$; el precio medio de un libro argentino rondaba los $50 \$$ y La vuelta de Martín Fierro, que acababa de aparecer, costaba 20 \$ (Pastormerlo 2006: 12). El título, el formato, y el precio son índice de la "abierta voluntad de llegar a un público amplio" (Prieto 1988: 43). En los dos primeros años aparecen 24 tomos, pero a partir de 1880 la publicación se hace irregular, y hasta 1883, en que La Biblioteca Popular de Buenos Aires deja de publicarse, se editan solamente 12 de los 48 tomos programados. Pastormerlo explica el fracaso del proyecto, observando que "el material publicado no buscaba ajustarse al gusto del nuevo público lector: esperaba, más bien una adecuación ('elevación') del público al material de lectura ofrecido" (Pastormerlo 2006: 14).

Sintomática es la reseña que escribe Vicente G. Quesada para el Anuario Bibliográfico de la República Argentina del año 1879. Allí elogia La Biblioteca Popular de Buenos Aires porque

expende alimento intelectual más sano y más barato: es la obra más fecunda y trascendente de un espíritu reflexivo y serio, que hace el bien sin obtener las ventajas de la popularidad de la plaza pública (Quesada 1880: 220).

Para Quesada, como para Navarro Viola, La Biblioteca... era "popular" porque iba dirigida al "pueblo", no porque tuviera en cuenta la "popularidad" en vistas de un posible éxito comercial (Pastormerlo 2006: 2) -una connotación que Navarro Viola había subestimado al planificar la colección, "empresa ajena a las protecciones oficiales y que solo busca y cuenta con la protección del pueblo", como observa optimista Vicente Quesada en su reseña de los primeros 24 tomos (Quesada 1880: 221).

Quesada subraya también que La Biblioteca Popular de Buenos Aires es "[a]ltamente moral en sus tendencias", a diferencia de "las fascinadoras producciones de Zola; las no menos peligrosas del actual Dumas, como el Affaire Clemenceau y tantas otras de la actual enfermiza literatura francesa" que deslumbran y seducen "por el realismo de los vicios soeces y por la fascinación colorida de la forma, enfermedades morales" peligrosas y difíciles de erradicar (Quesada 1880: 219). Al relacionar luego explícitamente la colección de Navarro Vio- 
la con las bibliotecas populares creadas en los años setenta, recuerda que un problema para surtirlas lo constituía la escasez de libros "en nuestro idioma" a precios accesibles, y remite al ejemplo de la Bibliothèque Rurale, una colección publicada en Bélgica, donde "la autoridad se preocupa de hacer ediciones de libros cuidadosamente elegidos, traduciéndolos, cuando era preciso, para formar con ellos la lectura popular de las campañas" (Quesada 1880: 221).

Para formar, a su vez, la lectura popular de los nuevos sectores urbanos en el Río de la Plata, y en competencia con los folletines "inmorales" que publican algunos diarios, La Biblioteca Popular de Buenos Aires otorga amplio espacio a la traducción de literatura contemporánea. Se publican en castellano obras de los franceses Eugène Scribe; Jules Sandeau; Alejandro Dumas hijo; Paul Féval; Octave Feuillet; Charles Baudelaire; Théophile Gautier; los italianos Edmondo de Amicis; Luigi Archinti; los alemanes Paul Heyse; Levin Schücking; los norteamericanos Nathaniel Hawthorne; Edgar Allan Poe y otros. Traducen para La Biblioteca Popular algunos de los miembros más destacados de la elite porteña: el mismo Miguel Navarro Viola, su hija, de la que se desconoce el nombre, y su hijo Enrique, Martín García Mérou, Carlos Olivera, Carlos Aldao, José Tomás Guido, Ernesto L. Negri, Bartolomé Mitre, Delfina Vedia de Mitre, Alejandro Korn, entre otros.

Sabemos quiénes tradujeron para la colección, porque sus nombres aparecen mencionados a continuación de los títulos de las obras traducidas, en la portada misma del número correspondiente. La lengua fuente es de preferencia el francés; cuando la traducción se efectúa de otra lengua, hay por lo general una mención explícita: " $\mathrm{La}$ carta robada, por Edgar Allan Poe, traducida del inglés por Carlos Olivera", "Desalientos, por Edmundo de Amicis, traducidos del italiano por E. L. Negri”, en los últimos volúmenes se suele agregar el dato de que se trata de una traducción inédita: "L'Arrabbiata por P. Heyse, trad. inédita del alemán por A. Korn”, otras veces se corrige una traducción ya existente: "La Nevada, por A. Puschkine, traducción corregida para La Biblioteca". Son escasos los títulos traducidos para los que no se hace mención del traductor; en tales casos, se trata seguramente de traducciones que circulaban ya, como era común en la época, de manera anónima. Con cierta frecuencia, en lugar del nombre aparecen las iniciales del traductor: M.N.V. es el director, S.N.V. es su 
hija, B.M. es Bartolomé Mitre, D.V. de M. su esposa, Delfina Vedia de Mitre. Las iniciales, en estos casos, no ocultan al traductor, sino que son una marca más fuerte de la visibilidad de las personalidades que traducen para La Biblioteca Popular, cuyos nombres se espera que sean reconocidos por las solas iniciales. Este detalle remite a un lector implícito diferente del lector al que se apela explícitamente, y es índice de la contradicción básica del programa.

En este nuevo proyecto de Navarro Viola hay, como en El Plata Científico y Literario, una clara política de visibilización del traductor. Esa estrategia es coherente con la importancia que le asigna Navarro Viola a la traducción, como lo hiciera explícito Vicente Quesada en su reseña: a falta de libros en castellano, hay que seleccionar y traducir convenientemente de otras lenguas textos que respondan a los objetivos pedagógicos del proyecto. La Biblioteca Popular de Buenos Aires es, en lo que a esto respecta, una institución clave del aparato de importación cultural de la segunda mitad del siglo XIX en el marco de construcción de una cultura nacional sobre el trasfondo del proceso inmigratorio.

\section{Las traducciones de Alejandro Korn para La Biblioteca Popular de Buenos Aires}

A diferencia de la literatura francesa, y en menor medida la italiana, en la segunda mitad del siglo XIX la literatura alemana contemporánea era poco conocida en el Río de la Plata. Dependía, para su difusión, de traducciones previas al francés o bien de mediadores específicos que no solamente conocieran la lengua, sino que tuvieran también acceso al mercado del libro alemán y -en lo que hace al proyecto de Navarro Viola- pudieran elegir textos adecuados a los objetivos de La Biblioteca Popular. Ese fue el caso de Alejandro Korn (18601936), hijo del médico alemán Adolfo Korn que había emigrado a la Argentina después de la revolución de 1848; el hijo se incorpora en 1878 al proyecto de Navarro Viola como traductor de literatura alemana contemporánea.

La referencia de Vicente Quesada a los efectos nocivos de la novela naturalista francesa, explica en buena medida los criterios de selección que pudieron llevar a Alejandro Korn a traducir del alemán textos de Heyse, Schücking y Lorm, autores hoy casi olvidados, pero 
que en su momento gozaban de gran popularidad dentro y fuera de Alemania. Tal es el caso de Paul Heyse y en particular de su relato "L'Arrabbiata", de 1857, traducido por Alejandro Korn y publicado en 1880 en el tomo XXVIII de La Biblioteca Popular de Buenos Aires.

Paul Heyse (1830-1914) escribió unos 180 cuentos, ocho novelas y casi 70 obras de teatro; fue traducido en vida a por lo menos 13 lenguas europeas ${ }^{14}$ y recibió en 1910 el "Premio Nobel de Literatura". Durante mucho tiempo fue el autor predilecto de los alemanes, desde la burguesía, para la que Heyse garantizaba la perduración de los ideales del clasicismo alemán, hasta los sectores populares urbanos, que simpatizaban con su crítica a la aristocracia y con la integridad de sus personajes pobres. Hacia 1885 comenzó a declinar su fama, criticado por los círculos naturalistas ahora consagrados, para los que Heyse era el paradigma de todo lo que había que superar en materia de literatura. Es evidente que el criterio de selección responde al anti-naturalismo de La Biblioteca Popular.

"L’Arrabbiata" es quizás el texto más famoso de Heyse, con 14 ediciones entre 1857 y 1914, sin tomar en cuenta las abundantes ediciones en volúmenes de conjunto (Ian 1965: 14). Para entender la elección del traductor, es necesario conocer la trama del relato. Cuenta una historia de amor cuya acción transcurre en el sur de Italia, entre Sorrento y la isla de Capri. El barquero Antonino está enamorado de la hiladora Laurella, a quien llaman l'Arrabbiata. Laurella lo desprecia; no quiere casarse, como le cuenta a su confesor, para evitar malos tratos como los sufridos por su madre a manos de su padre. En el trayecto de Capri a Sorrento, Antonino, herido por el desprecio de Laurella, que es su única pasajera, en un arranque de desesperación trata de matarla y de suicidarse, pero ella se arroja al mar y nada hacia la costa. Antonino comprende que ha ido demasiado lejos, se arrepiente, la rescata, la deposita sana y salva en tierra firme y decide renunciar a ella; pero Laurella, también arrepentida de haberlo tratado tan mal, va a visitarlo esa misma noche, le cura la herida que ella misma le infligió, y la historia tiene un final feliz.

14 El Archivo Heyse registra traducciones al danés, inglés, francés, italiano, finlandés, ruso, español, holandés, griego moderno, noruego, polaco, rumano, sueco y esperanto (Ian 1965: 31). 
Podría pensarse que "L'Arrabbiata", con su escenario italiano y sus personajes humildes que consiguen controlar sus pasiones y obtienen como recompensa la felicidad y el amor, responde perfectamente al objetivo de moralización de los sectores populares inmigratorios. Un análisis de las estrategias de traducción permite comprobar que Alejandro Korn ha censurado fuertemente el texto fuente al traducir1o. ${ }^{15}$ El texto fuente tiene 6.934 palabras, la traducción 3.936; si consideramos, además, que el alemán es una lengua aglutinante, y el castellano no, podríamos decir que la traducción reduce el texto a la mitad. La censura más evidente se ejerce sobre el relato de Laurella acerca de los malos tratos sufridos por la madre, incluida la descripción sugerida de una escena de violación en el matrimonio, que queda reducido a un par de frases estereotipadas: "Mi padre le hacia sentir [a mi madre] todo el peso de su mal humor y no le ahorraba sufrimiento alguno. Luego se arrepentía y trataba de reparar el mal que habia hecho" (Heyse 1880: 206). ${ }^{16}$ Falta, además, la escena final en que Laurella y Antonino se reconcilian y se confiesan su amor; en la traducción, esa escena, de unas 500 palabras, queda reducida a la frase "El hielo estaba roto" y una línea de puntos suspensivos que no está en el texto fuente (Heyse 1880: 217).

Heyse no escribía para que el lector alemán se identificara moralmente con los personajes de "L'Arrabbiata", sino que lo inscribía como espectador de una historia pintoresca que transcurría en la bella Italia. Alejandro Korn, en cambio, traduce "L'Arrabbiata" para que sus lectores, provenientes de los sectores populares, en parte tal vez inmigrantes o hijos de inmigrantes, se identifiquen con los personajes protagónicos y sus conductas, y prefiere evitar escenas escabrosas y levemente eróticas, que no condicen con la "tendencia altamente mo-

15 Si bien, como señala Gouanvic (2007: 133), toda traducción censura, en la medida en que expresa lo que resulta decible del texto fuente en un campo y en una época dados, hay traducciones que censuran más que otras, y este es uno de esos casos.

16 Una traducción más literal de esta escena podría ser la siguiente: "La maltrataba, le pegaba y la pisoteaba. Recuerdo las noches en que él volvía a casa malhumorado y agresivo. Ella nunca le decía nada y hacía todo lo que él quería. Pero él le pegaba tanto, que se me estremecía el corazón. Entonces me tapaba la cabeza con la colcha y fingía dormir, pero lloraba toda la noche. Y cuando él la veía tirada en el piso, de repente se transformaba, la levantaba y la besaba hasta hacerle gritar que la estaba asfixiando". 
ral" que Quesada le atestaba a La Biblioteca Popular de Buenos Aires y con el proyecto pedagógico al que respondía la colección.

En coherencia con esa misma lógica se omiten en la traducción consecuentemente elementos pintoresquistas, produciendo un efecto de aclimatación. Desaparecen pequeños cuadros de costumbres, detalles que dan plasticidad a las descripciones, términos en italiano incluidos en los diálogos y topónimos; con excepción de Laurella se castellanizan todos los nombres y otros términos que Heyse escribe en italiano.

En lo que respecta a los niveles de lengua, el texto fuente abunda en giros coloquiales y marcas de oralidad en el discurso directo, mientras que la traducción mantiene el mismo nivel de lengua para el narrador y los personajes, caracterizado por la ausencia de giros coloquiales y de marcas de oralidad. Domina, por el contrario, un estilo que remite a la lengua escrita: Korn no traduce los diminutivos, privilegia la anteposición del adjetivo en las construcciones nominales ("la renegrida trenza", "las espaciosas grutas"), traduce fórmulas breves y coloquiales en estilo elevado; ${ }^{17}$ evita la doble negación, ${ }^{18}$ utiliza consecuentemente la sufijación del pronombre ("inclinábase", "dícese"), etc.

Si el nivel de lengua confronta al lector con un estilo que no responde al uso coloquial del castellano rioplatense, pero sí a los objetivos pedagógicos de la colección, la tipografía le facilita en cambio la lectura. La traducción utiliza guiones de diálogo y segmenta el texto separando claramente las voces de los diversos personajes y la voz del narrador, mientras que el texto fuente no disocia tipográficamente las voces de los personajes y la del narrador, ni marca el cambio de hablante en los diálogos. Estos cambios producen un efecto de estilo que transforma la "eficacia discursiva" de la traducción respecto del texto fuente (Gouanvic 2007: 130). La tipografía del texto fuente exige un lector que distinga las voces y los niveles de lengua, mientras que la traducción, al marcar los cambios de hablante, requiere una

17 Por ejemplo: "Nach einer Pause", que podría traducirse como "Tras una pausa" se traduce como "Sobrevino un momento de silencio".

18 Le hace decir a Laurella, en un estilo carente de toda coloquialidad: "no le ahorraba sufrimiento alguno", o "yo nada les hago". 
competencia de lectura menos desarrollada, acorde con la imagen del lector al que se dirige la Biblioteca Popular de Buenos Aires. ${ }^{19}$

\section{Conclusiones}

No sólo el texto fuente, sino también la cultura receptora, y específicamente las instituciones del aparato importador, condicionan la práctica del traductor. ${ }^{20}$ Miguel Navarro Viola traduce "Graziella" para un público letrado al que ve en peligro de caer en el consumo del folletín mal traducido y peor escrito. Su preocupación no es la lectura del público popular, que guiaba a Lamartine, sino la lectura del público letrado, para quien Navarro Viola traduce con una estrategia de no-aclimatación que exige del lector un acercamiento al texto, respetando la dicción del original, y poniendo en juego una noción de estilo del traductor como escritor. Podría decirse que Navarro Viola traduce para potenciales traductores, pero también para futuros escritores, y también con el objetivo de acumular capital simbólico en el marco de la construcción de una literatura nacional.

Alejandro Korn adecua su traducción de "L'Arrabbiata" a los objetivos pedagógico-moralizantes de La Biblioteca Popular de Buenos Aires ante el surgimiento de un público lector de carácter popular que no existía aun en los tiempos de El Plata Científico y Literario. La práctica traductora de Korn es altamente heterónoma: sus estrategias de traductor de literatura alemana responden al proyecto letrado de pedagogía cultural que anima la edición de La Biblioteca Popular de Buenos Aires. Pero ese emprendimiento no tiene el éxito que se esperaba y la colección se clausura antes de tiempo, porque la agenda pedagógica de los letrados que habían lanzado el proyecto era incongruente con la demanda de los nuevos lectores. Este fracaso revela la contradicción básica del proyecto letrado de educar al pueblo a través de la literatura sin tomar en cuenta la demanda del público.

19 Para un análisis pormenorizado de la traducción de Alejandro Korn ver Pagni (2011).

20 Utilizo aquí el término "prácticas" siguiendo a Gouanvic, para quien la noción de "práctica" tiene que ver con una disposición, un "habitus" en el sentido de Bourdieu; el sentido práctico del traductor es su capacidad de producir una traducción que se inscriba adecuadamente en una situación dada del campo (Gouanvic 2007: 120). 
Unos veinte años más tarde, en 1901, se lanza la Biblioteca de "La Nación", cuyos objetivos pedagógicos son similares, pero que, a diferencia de La Biblioteca Popular de Navarro Viola, sí tiene en cuenta el juego de oferta y demanda del mercado editorial (Willson 2005). A lo largo de casi veinte años, se publican más de 800 volúmenes, en su mayor parte traducciones, buenas y malas, como diría Navarro Viola, que contribuirán a formar a ese nuevo público lector popular surgido de la inmigración, constituyéndolo como un público nacional, en la medida en que la literatura extranjera, leída masivamente, será entonces sí parte de un imaginario compartido.

\section{Bibliografía}

Bertoni, Lilia Ana (2001): Patriotas, cosmopolitas y nacionalistas. La construcción de la nacionalidad argentina a fines del siglo XIX. Buenos Aires: Fondo de Cultura Económica.

Eujanián, Alejandro (1999): "La cultura: público, autores y editores". En: Bonaudo, Marta (ed.): Liberalismo, Estado y Orden Burgués (1852-1880). Nueva Historia Argentina. Tomo IV. Buenos Aires: Sudamericana, pp. 545-605.

Even-Zohar, Itamar ([1990] 2004): "The Position of Translated Literature within the Literary Polysystem". En: Venuti, Lawrence (ed.): The Translation Studies Reader. London/New York: Routledge, pp. 199-204.

Fortescue, William (1983): Alphonse de Lamartine. A Political Biographie. London/ Canberra/New York: Crom Helm/St. Martin's Press.

Gleize, Joëlle (1997): "Graziella, une socio-physiologie de la lecture naïve". En: Romantisme, 95, 1, pp. 51-60.

Gouanvic, Jean-Marc (2007): Pratique sociale de la traduction. Le roman réaliste américain dans le champ littéraire français (1920-1960). Arras: Artois Presses Université.

Heyse, Pablo (1880): “L’Arrabbiata”. Traducida del alemán para la Biblioteca Popular de Buenos Aires por Alejandro Korn. En: Biblioteca Popular de Buenos Aires XXVIII, pp. 206-217.

Ian, Annemarie von (1965): Die zeitgenössische Kritik an Paul Heyse 1850-1914. Tesis de doctorado, Man. München.

Lamartine, Alphonse de (1854): "Graziella". Traducción de Miguel Navarro Viola. En: El Plata Cientifico y Literario, 1, pp. 162-203.

- (1979): Graziella. Édition présentée, établie et annotée par Jean-Michel Gardair. Paris: Gallimard.

Navarro Viola, Miguel (1854a): "Prospecto". En: El Plata Científico y Literario, 1, pp. 1-7.

- (1854b): “'Graziella' por Alfonso de Lamartine”. En: El Plata Cientifico y Literario, 1, pp. 161-162. 
Pagni, Andrea (2011): "La importación de literatura alemana en Argentina hacia 1880: Alejandro Korn en La Revista Popular de Buenos Aires". En: Pagni, Andrea/Payàs, Gertrudis/Willson, Patricia (eds.): Traductores y traducciones en la historia cultural de América Latina. México, D.F.: El Colegio de México.

Pastormerlo, Sergio (2006): “1880-1899. El surgimiento de un mercado editorial”. En: Diego, José Luis de (ed.): Editores y políticas editoriales en Argentina, 18802000. Buenos Aires: Fondo de Cultura Económica, pp. 1-28.

Prieto, Adolfo (1988): El discurso criollista en la formación de la Argentina moderna. Buenos Aires: Sudamericana.

Quesada, Vicente (1880): “La Biblioteca popular de Buenos Aires dirigida por Miguel Navarro Viola. Del tomo XII al XVI". En: Anuario Bibliográfico de la República Argentina. Vol. I (1879): pp. 217-223

(<www.cervantesvirtual.com/servlet/SirveObras/01604074347838285212257/ p0000001.htm\#I_0_>, 14.09.2010).

Venuti, Lawrence (2005): "Local Contingencies: Translation and National Identities". En: Bermann, Sandra/Wood, Michael (eds.): Nation, Language, and the Ethics of Translation. Princeton: Princeton University Press, pp. 177-202.

Willson, Patricia (2005): "Elite, traducción y público masivo". En: Estudios. Revista de Investigaciones Literarias y Culturales, 25, pp. 235-252.

- (2008): "El fin de una época: letrados-traductores en la primera colección de literatura traducida del siglo xx en la Argentina”. En: TRANS. Revista de traductología, 12, pp. 29-42. 